\title{
INTENSITY OF INNOVATION ACTIVITY AND ITS PROGRESSIVITY IN ENTERPRISES IN SLOVAKIA IN THE ERA OF INDUSTRY 4.0
}

\section{aPATRIK RICHNÁK}

University of Economics in Bratislava, Faculty of Business Management, Department of Production Management and Logistics, Dolnozemská cesta 1, 85235 Bratislava, Slovak Republic

email: ${ }^{a}$ patrik.richnak@euba.sk

The paper is a partial output of VEGA No. 1/0375/20 research project titled „New dimension in the development of production management and logistics under the influence of Industry 4.0 in enterprises in Slovakia“.

Abstract: At present, it is not easy to define and recognise the innovative potential of an enterprise in a market environment. It is about identifying the components, relationships and understents, expected ections expected economic, social, environmental consequences of introducing and managing in marke competitive positions as well as to seek a sustainable competitive advantage. The paper's main goal was to examine the degree of the introduction of innovations in enterprises in Slovakia in the era of Industry 4.0 on the basis of a knowledge base and a questionnaire survey. By applying theoretical knowledge and statistical methods of evaluating the questionnaire survey, we came to potential opportunities for the development of innovation activity in the ongoing fourth industrial revolution in the surveyed enterprises.

Keywords: innovation activity, innovation development, innovation potential, digitisation, Industry 4.0

\section{Introduction}

It is not easy to define and recognize the innovative potential of an enterprise in a market environment. It is about identifying the components, relationships and understanding the concepts, interconnections and achieving the expected economic, social, environmental consequences of introducing and managing innovation.

The development of countries and enterprises is responsible for many changes in the world economy, which determines their future influence and success on the market. For this reason, businesses must be able to respond promptly to these changes. For several years, researchers have been researching what type of business is most likely to succeed in the innovation market and progress in their research activities. It is also essential to define what primary attributes must be met, the subject of the business, how long it has been operating in the market, etc.

Innovation can be seen as a renewal or improvement of existing, well-established things and phenomena with reintroduction into practice. Although, as an abstract concept, innovation is generally very important because it moves businesses and their activities forward, it should be mentioned that innovation can also have no benefit for the enterprise. We also meet with the opinions that bad innovation also contributes to the improvement of processes in the future, as long as the enterprise can identify it and convert it to its advantage only in case it is not liquidating for the enterprise at the outset.

\section{Theoretical overviews}

Innovation consists of creating a new idea and then implementing it in a new product, process or service. This leads to dynamic growth in the national economy and increased employment, as well as generating a net profit for the innovative enterprise (Kogabayev and Maziliauskas, 2017). According to Blindenbach-Driessen and van den Ende (2014), innovation is associated with increased performance, the creation of new markets and competitive advantage. Businesses are innovating to defend their existing competitive positions as well as to seek a sustainable competitive advantage. The term innovation includes new technological, economic, social and organizational solutions that are not necessarily marketable, in the economic sense and direct monetary impact, but are applicable and are being used within organizations (Silva et al., 2016). Innovations are a proportionately significant factor in enterprises in various fields. The OECD defines an innovation as a new or improved product or process (or their combination) that differs significantly from the units of previous products or processes and has been made available to potential users (product) or has been put into use by the unit (process) (OECD/Eurostat, 2018).

Innovation can come from two sources: marketing and technology. Some products may require a coinciding of the two sources (Garcia, 2002). In addition, different types of innovation require different competencies, resources, knowledge and investments, leading to different potential risks (Smith and Tushman, 2005).

It is possible to classify and differentiate innovation using various metrics such as the object of innovation and the rate of innovation. Innovation in a firm may be non-technological, such as organizational and marketing innovation, and technological, such as product and process innovation (Geldes et al., 2017). We can classify innovations as product innovations, process innovations, marketing innovations and organisational innovations (European Commission/Eurostat, 1997). Piao and Zajac (2015) identified two types of use of innovations: reproduced use (repetition of existing designs for existing products) and incremental exploitation (creation of new designs for existing products). The authors concluded that these two uses have different effects during the survey. Utilisation can be defined as the gradual improvement of an existing product business aimed to improve the current domain product market, and the survey can be seen as the development of new products aimed at new areas of the product market. Szopik-Depczyńska (2015) distinguishes between different types of innovations that have different spheres of influence. In particular, product innovations relate to the impact of competition, demand and the market and are intended to replace products withdrawn from the market; expand the firm's offer in terms of products and services; create products that are environmentally friendly; increase or maintain market share; and enable the firm to enter new markets. Gubová (2020a) combines innovation with technology. The author says that innovations, especially in logistics activities, are in the midst of dynamic changes and enterprises must continuously manage and monitor them during everyday business activities, which affects the efficiency and effectiveness of production.

Enterprises can differentiate their innovation strategy between their exploitative strategy, which refers to presently employed technologies and tasks, and their exploratory strategy, which consists of technologies and tasks that are novel or radical (Jansen et al., 2006). Prange and Schlegelmilch (2016) have developed proposals to explain the interaction between different types of innovative paradigms of use and present the results of a survey that reflects the belief that enterprises are simultaneously or sequentially able to embrace several types of innovation. The survey leads to entirely new innovations and the use and maintenance of existing innovations. Businesses prefer innovations with long life cycles; however, mixing and overlapping them can lead to reduced performance.

The process of innovation development may vary from company to company, influenced, among other things, by the sector of activity or the size of the enterprise (Conde and Araújo-Jorge, 2003). Many foreign empirical studies have not established a clear relationship between enterprise size, market power and innovative activity. Baruk (2015) defines innovation activity as an ordered set of scientific, technical, organizational, financial, managerial and business activities carried out to develop and implement innovations. We consider business innovation a new or improved product or business process that differs significantly from business predecessors or business processes. A new or improved product has been introduced to the market or put into 
use by enterprises. Some studies define business innovation as the result of competition in the market.

If the innovation leads to better products, lower costs, better or new features, it can also be classified in terms of the scope of function, i.e. to what extent the old product becomes a product with improved capability. This is the so-called economic (competitive) view. In this case, innovation is said to be radical if it results in a better product (lower costs, better attributes or new attributes), and existing products become functionally incapable of covering the new functions of the innovated product and are unable to compete in the market environment (Scuotto, and Shukla, 2015).

Digital technologies have nowadays a significant impact on how new business ventures are imagined and created. The arising technology paradigm is leveraging the potential of collaboration and collective intelligence to design and launch more robust and sustainable entrepreneurial initiatives (Elia et al., 2020). Some studies, such as Bouncken et al. (2019), examine the integration of digital technologies and their use in new business models. The challenge for businesses is the degree to which businesses are involved in digital transformation and digitisation. Businesses can apply digital technologies to improved or new internal and external processes and integrate them into new business models. The digital transformation itself in the enterprise requires extensive knowledge from different backgrounds. Vial (2019) defines digital transformation as a process that aims to improve an entity by inducing significant changes in its characteristics through a combination of information, computing, communication and connectivity technologies. Ongoing advances in artificial intelligence, digitisation, connectivity, smart machines and the Internet of Things (IoT) have brought about a digital transformation that ushers in a new era of technological development in the form of the 4th Industrial Revolution, also known as Industry 4.0 (Behrens and Trunschke, 2020). The fourth industrial revolution (Industry 4.0) is related to digitisation, augmented reality, automation, and intelligent technologies (Gubová, 2020b). The fourth industrial revolution represents a fundamental digital transformation. This revolution is known around the world as Industry 4.0, and it is advancing exponentially (Ghobakhloo, 2020). Industry 4.0 is associated with terms such as Cyber-Physical Systems (CPS), Internet of Things (IoT), Internet of Services (IoS), Robotics, Big Data, Cloud Manufacturing and Augmented Reality and will narrow the gap between the physical and the digital world (King and Grobbelaar, 2020).

An enterprise with a high market orientation will have more knowledge about the market in terms of customers and competitors; in this case, the knowledge of the external market acquired by the enterprise will vary in the amount of information, information channels and degree of difficulty, making it easier for enterprises and enterprise members to obtain more external relevant information (Martín-de Castro, 2015).

The combination of solid market interconnection and dynamic market turbulence can increase new product development performance. Conversely, customer preferences often do not change with low market turbulence, even with high market orientation. Team members will think that customer demand is the same or similar and will reduce members' motivation to absorb information (Chen et al., 2016). When we talk about developing change and making some progress, we are thinking about transferring ideas, technologies, and so forth. Horizontal progress means copying things that already work - from 1 to n. Horizontal progress (globalisation) is easy to imagine because we already know what it looks like. Vertical (technology) or intense progress means doing new things from 0 to 1 . Vertical progress is harder to imagine because it requires something that no one else has ever done (Thiel and Masters, 2015).

Emerging businesses are very active in gaining knowledge from different sources and geographical areas, but these activities may reduce growth for top enterprises in the future (Huggins et al., 2015).
The last decade has been very progressive in terms of the promising technological advancements and transformations. New technologies are converging and making our life easier and more efficient and yet we are likely to see disruptive innovations that have never been considered before (Khan, 2019). Technological developments suggest that the importance of user innovation is likely to increase due to the growing importance of the internet, which connects communities, facilitates the exchange of ideas, access to complementary skills. According to Rayna et al. (2015), a shift in technological development can also be seen in process innovation such as 3D printing and other flexible processing technologies that allow users to produce individual products from digital models at relatively low cost. Economic implications of 3D printing and significance analysis of "Big Data" examined and in their study Kaulartz and von Hippel (2018). The main competence of 3D printing is to fabricate the products closer to the expectations of customers around the world and to customise those products in real time (Varsha Shree et al., 2020).

\section{Research methodology and description of statistical data}

The main goal of this research paper was to examine the degree of the introduction of innovations in enterprises in Slovakia in the era of Industry 4.0 on the basis of a knowledge base and a questionnaire survey. By applying theoretical knowledge and statistical methods of evaluating the questionnaire, we came to potential opportunities for the development of innovation activity in the ongoing fourth industrial revolution in the surveyed enterprises.

One hundred thirty-five enterprises operating in Slovakia took part in the questionnaire survey. Table 1 displays the share of respondents by the size of the enterprise. Small and mediumsized enterprises accounted for $63 \%$ of the total number of respondents involved. The second-largest share of respondents was represented by micro-enterprises with a share of $20.7 \%$, and large enterprises formed the share of $16.3 \%$. Based on quantifying the number of enterprises according to the Statistical Office of the Slovak Republic, the most numerous microenterprises are in Slovakia. In the survey, the largest group consisted of small businesses with a share of $37.8 \%$. The research results showed that small and medium-sized enterprises are in the early stages of implementing Industry 4.0 elements. The mentioned structure of enterprises by size should be a model structure of the real state of enterprises performed by the Statistical Office of the Slovak Republic, as the fact that microenterprises are the most numerous in Slovakia does not create optimistic forecasts in the field of innovation development. Medium and large enterprises have an ideal business and market environment for developing innovation and strengthening the country's innovation potential. The intention should be state support for small and medium-sized enterprises, as they are currently inactive in the field of innovation. It is perhaps through the support of the levy and social area that this structure would change.

Table 1: Structure of the surveyed enterprises by enterprise size

\begin{tabular}{|c|c|}
\hline Enterprise size & Percentage \\
\hline Micro enterprises & $20.7 \%$ \\
\hline Small enterprises & $37.8 \%$ \\
\hline Medium-sized enterprises & $25.2 \%$ \\
\hline Large enterprises & $16.3 \%$ \\
\hline
\end{tabular}

Source: author's processing

Based on the primary goal of the submitted paper, the following hypothesis was determined and tested:

$H_{0}$ : We assume no significant positive relationship between the size of the enterprise and the level of innovation implementation rate.

$H_{1}$ : We assume a significant positive relationship between the size of the enterprise and the level of innovation implementation rate. 
In the framework of implemented research, there were several quantitative and expert research methods used. Methods of analysis and synthesis, induction and deduction, comparison and scientific abstraction were used to process the knowledge base. Pearson's $\chi 2$-independence test was used to verify the association to evaluate the data from the questionnaire survey. This test is also called the Chi-square homogeneity test. The basis of the test is to compare the agreement of theoretical frequencies with the found frequencies and to assess the significance of the differences between them. The condition to use the test is that the sample size is greater than $20(n>20)$ and that all theoretical frequencies are at least $5\left(E_{i j} \geq 5\right)$. Fisher's exact test is another method of measuring the association between variables. It does not depend on the fulfilled conditions for a distribution with a sufficiently large sample, and therefore it is suitable to be used on small samples or weaker data, or unfulfilled conditions for the use of Pearson's Chi-square test $\left(n>20 ; E_{i j}>=5\right)$. Another statistical method for the data evaluation from the questionnaire survey was correlation analysis (Pearson's correlation coefficient), which examines the tightness of statistical dependence between quantitative variables. Pearson Correlation and Spearman Correlation were applied for statistical verification. The results of the statistical tests are evaluated in Table 2.

Table 2: Results of the calculation of statistical data

\begin{tabular}{|c|c|c|}
\hline \multicolumn{2}{|c|}{ Fisher's Exact Test } & \\
\hline Table Probability (P) & $<.0001$ & \\
\hline Pr <= P & 0.0002 & \\
\hline Statistic & Value & ASE \\
\hline Pearson Correlation & 0.5112 & 0.0686 \\
\hline Spearman Correlation & 0.5486 & 0.0726 \\
\hline
\end{tabular}

Source: author's processing

Critical area $\chi_{\mathrm{p}}^{2}>\chi_{1-\alpha}^{2}[(\mathrm{r}-1) *(\mathrm{~s}-1)]$ where $\alpha$ is the selected level of significance, respectively $(1-\alpha)$ is reliability. $\chi_{1-\alpha}^{2}[(\mathrm{r}-1)$ * (s-1)] represents the value that can be found using statistical software. Based on the calculation, we can conclude that if the inequality applies, we accept hypothesis $\mathrm{H}_{1}$ and confirm the dependence. If the inequality does not apply, we do not have enough evidence to reject hypothesis $\mathrm{H}_{0}$ and thus cannot confirm the dependence between the characters A and B.

Based on the results in Table 2 (testing the established hypothesis), we concluded that there is a significant positive relationship between the size of the enterprise and the level of innovation implementation, which accepts hypothesis $\mathrm{H}_{1}$ and hypothesis $\mathrm{H}_{0}$ is rejected.

\section{Research results and discussion}

At present, the innovation of undertakings also depends on the level of use of high-tech technology, resulting in the satisfaction of growing customer demands for quality, cost reduction, and rapid implementation of products. It is one of the solutions to the dynamic development of the industry at home and abroad. Hightech is closely linked to intelligent technologies, the Internet of Things (IoT), digitisation from primary production - raw material processing to product recycling. The effectiveness of enterprises' investment in innovation currently depends, in addition to finances, also on the size of the enterprise, the set strategic goals and the subject of the enterprise's activity.

Table 3 presents the share of innovations introduced in enterprises by enterprise size. A high share of implemented innovations was formed by non-technological innovations, marketing and organisational innovations with a share of $48.40 \%$. With this percentage, these innovations are being introduced by large enterprises. The high share of this type of innovation is based on the connection between the organisation of processes, delegation and planning of new activities related to innovation changes in the enterprise. Furthermore, they are the activities of the organisation of production strategy, organisation of innovation forecasting, organisation of development processes, production preparation, production logistics, essential production and post-production activities. The need for organisational innovation is caused by constant changes in products in technologies that need to be harmonised and organised. Based on table 3 , we can see that medium-sized enterprises implement technological innovations the most. The percentage was $45 \%$. We attribute this to the progressive growth of the use of technology, automation and the introduction of digitisation in enterprises. Micro-enterprises implement the most minor technological innovations with a share of $9 \%$. Process innovations are implemented by large enterprises with a share of 33.3\%. Medium-sized enterprises also had almost the same percentage when implementing process innovations. The percentage of the introduction of process innovations in these enterprises was $30.1 \%$. The most minor process innovations are implemented by micro-enterprises, where the share was $12.4 \%$.

Table 3: Proportion of innovation introduced in enterprises, expressed as a percentage by enterprise size

\begin{tabular}{|c|c|c|c|}
\hline & $\begin{array}{c}\text { Technological } \\
\text { innovations }\end{array}$ & $\begin{array}{c}\text { Process } \\
\text { innovations }\end{array}$ & $\begin{array}{c}\text { Non- } \\
\text { technological } \\
\text { innovations }\end{array}$ \\
\hline $\begin{array}{c}\text { Micro } \\
\text { enterprises }\end{array}$ & $9 \%$ & $12.4 \%$ & $2.1 \%$ \\
\hline $\begin{array}{c}\text { Small } \\
\text { enterprises }\end{array}$ & $18 \%$ & $24.2 \%$ & $25.8 \%$ \\
\hline $\begin{array}{c}\text { Medium- } \\
\text { sized } \\
\text { enterprises }\end{array}$ & $45 \%$ & $30.1 \%$ & $23.7 \%$ \\
\hline $\begin{array}{c}\text { Large } \\
\text { enterprises }\end{array}$ & $28 \%$ & $33.3 \%$ & $48.4 \%$ \\
\hline Total & $100 \%$ & $100 \%$ & $100 \%$ \\
\hline Source: author's processing & & \\
\hline
\end{tabular}

In connection with this question, we asked respondents about the intensity of how enterprises implement individual types of innovation. Technological innovations are implemented by $42 \%$ of enterprises, and process innovations are applied by $33 \%$ of enterprises in the range of $21 \%-40 \%$. Non-technological innovations are implemented by $47.4 \%$ of enterprises in the range of $1 \%-20 \%$.

At present, great attention is paid to introducing individual principles, elements, technologies of Industry 4.0. Based on this fact, in the questionnaire survey, we dealt with the level of implementation of innovations in the conditions of Industry 4.0, in order to achieve competitiveness and sustainability of the enterprise in the market. The results are shown in Table 4 . The increase in labour productivity with a share of $51.1 \%$ is one of the most critical areas for the introduction of innovations in the conditions of Industry 4.0 in enterprises in Slovakia. For $48.9 \%$ of enterprises, the introduction of innovations in the conditions of Industry 4.0 means saving time. For $44.4 \%$ of respondents, the implementation of innovations represents a financial saving. Enterprises with a share of $40 \%$ consider the importance of innovation in the form of streamlining enterprise processes.

Table 4: Significance of the introduction of innovations in the conditions of Industry 4.0 in enterprises in percentages according to the scale (1-most significant and 5-least significant)

\begin{tabular}{|c|c|c|c|c|c|}
\hline & $\mathbf{1}$ & $\mathbf{2}$ & $\mathbf{3}$ & $\mathbf{4}$ & $\mathbf{5}$ \\
\hline Timesavings & $48.9 \%$ & $30.4 \%$ & $13.3 \%$ & $4.4 \%$ & $3 \%$ \\
\hline Money savings & $44.4 \%$ & $25.9 \%$ & $18.5 \%$ & $8.2 \%$ & $3 \%$ \\
\hline $\begin{array}{c}\text { Streamlining } \\
\text { enterpriseprocesses }\end{array}$ & $40 \%$ & $29.6 \%$ & $20.7 \%$ & $5.9 \%$ & $3.7 \%$ \\
\hline $\begin{array}{c}\text { Increasing labour } \\
\text { productivity }\end{array}$ & $51.1 \%$ & $25.9 \%$ & $14.1 \%$ & $5.9 \%$ & $3 \%$ \\
\hline
\end{tabular}

Source: author's processing

If an enterprise introduces innovations in the field of saving materials and streamlining enterprise processes, it succeeds in reducing maintenance costs. Quality as the main effect brings 
streamlining of enterprise processes and increasing labour productivity. Innovations introduced in Industry 4.0 conditions to reduce maintenance costs and increase productivity will reduce overall machine downtime. Increasing productivity in technical professions through automation leads to reduced overall machine downtime and an increase in overall productivity. By increasing productivity in technical professions through the automation of work, there is a decrease in stocks due to increased forecasting reliability. The shortening of the time of entry into the market with innovation is caused by the accuracy of the forecast, the reduction of stocks and the increase of quality and productivity in the enterprise. The time factor is essential in the implementation of innovations and the mutual influences of the introduced innovations on the savings of materials and energy, resulting in savings of time and finances, which in turn leads to streamlining processes in the enterprise. Saving time is equal to saving money. This confirms the business rule that time is money. Innovations in the field of saving materials and energy lead to saving time, money, streamlining enterprise processes and increasing labour productivity.

\section{Conclusion}

The survey aimed to examine the degree of the introduction of innovations in enterprises in Slovakia in the era of Industry 4.0. Based on the evaluation of data and processing of results, we concluded that the largest group in the survey consisted of small enterprises in Slovakia. These enterprises were represented in the survey with a share of $37.8 \%$. We discovered that a high proportion of implemented innovations were non-technological innovations, marketing and organisational innovations from the evaluated data. These innovations accounted for $48.4 \%$ and are being introduced by large enterprises in Slovakia. From the processed data from the questionnaire, we also found out the level of introduction of innovations in the conditions of Industry 4.0. The increase in labour productivity with a share of $51.1 \%$ was one of the most critical areas for the introduction of innovations in enterprises in Slovakia. A significant positive relationship between the size of the enterprise and the level of innovation implementation was also confirmed.

The studies' results help enterprises obtain market and technological information more accurately, to transform available knowledge into their absorption capacity, to improve the performance of new product innovations and achieve a competitive advantage of absorption capacity.

New competitors in the market increase competitive strength, thereby reducing profit margins. The availability of close substitutes makes it difficult for the manufacturer to increase prices, with customers expecting products imitating competitors with lower prices. Suppliers can increase manufacturers' costs, while customers can benefit from margins in the form of lower customer prices and increased selling costs. In attractive industries, not all enterprises achieve sales. In fact, in an unattractive industry, there may still be some enterprises that generate revenue. In other words, within each industry, some enterprises will have a competitive advantage. They will, on average, be more profitable than their competitors and will also have innovation potential. An enterprise can offer cheaper or more differentiated products than its competitors if it has capabilities that cannot be easily imitated or traded. The basis of the enterprise is the ability to develop and use technology and knowledge of the market. The ability of enterprises to take advantage of innovation is a function of the extent to which they own or can build rare, complex imitation capabilities that are key to its value configuration (value chain, value network, value trade). We consider imitations to be an incentive in the development of new products and services. An imitator can motivate competing enterprises in a given market segment and can undertake new activities and generate new ideas. Imitations within the strategic position of enterprises create new forces and pressures within the market and force enterprises to constantly bring new ideas and fill market gaps. If managers underestimate the importance of user innovation, they are unlikely to realise the full potential of this key innovation.
Industry 4.0 will change enterprises' nature and increase the demands and requirements for skilled workers. The demand for labour will continue to grow as new professions emerge in enterprises to reflect on the digitisation of production and logistics.

In conclusion, given the changing consumer demand and cyclical technological improvements, it is necessary to manage innovation planning and build coherence between changing strategic plans and innovation initiatives. In order to increase efficiency, plan and manage the innovation process to suit the optimal time and product implementation process. Due to the shorter product life cycle, to produce practical improved new products to remain competitive, while emphasising the prolongation of the product life cycle on the market to reduce the environmental burden. Also, emphasise the precise planning, monitoring, control of spent and planned investment costs for research and development, as it is a way to be successful in the domestic and foreign markets.

\section{Literature:}

1. Baruk, J. (2015). Innovation activity management in scientific and research and development organizations. Marketing of Scientific and Research Organisations. 17(3). 121-145. doi: 10.14611/minib.17.03.2015.12.

2. Behrens, V., Trunschke, M. (2020). Industry 4.0 Related Innovation and Firm Growth. SSRN Electronic Journal. doi:10.2139/ssrn.3739871

3. Blindenbach-Driessen, F., van den Ende, J. (2014). The Locus of Innovation: The Effect of a Separate Innovation Unit on Exploration, Exploitation, and Ambidexterity in Manufacturing and Service Firms. Journal of Product Innovation Management, 31(5), 1089-1105. doi:10.1111/jpim.12146

4. Bouncken, R. B., Kraus, S., Roig-Tierno, N. (2019). Knowledge- and innovation-based business models for future growth: digitalized business models and portfolio considerations. Review of Managerial Science, 15(1), 1-14. doi:10.1007/s1184 6-019-00366-z

5. Conde, M. V. F., Araújo-Jorge, T. C. de. (2003). Modelos e concepções de inovação: a transição de paradigmas, a reforma da C\&T brasileira e as concepções de gestores de uma instituição pública de pesquisa em saúde. Ciência \& Saúde Coletiva, 8(3), 727-741. doi:10.1590/s1413-81232003000300007

6. Elia, G., Margherita, A., Passiante, G. (2020). Digital entrepreneurship ecosystem: How digital technologies and collective intelligence are reshaping the entrepreneurial process. Technological Forecasting and Social Change, 150, 119791. doi:10.1016/j.techfore.2019.119791

7. European Commission/Eurostat (1997). Proposed Guidelines for Collecting and Interpreting Technological Innovation Data. The Measurement of Scientific and Technological Activities. [viewed 2021-05-25]. Available from: https://www.oecd.org/sci ence/inno/2367614.pdf

8. Garcia, R. (2002). A critical look at technological innovation typology and innovativeness terminology: a literature review. Journal of Product Innovation Management, 19(2), 110-132. doi:10.1016/s0737-6782(01)00132-1

9. Geldes, C., Felzensztein, C., Palacios-Fenech, J. (2017). Technological and non-technological innovations, performance and propensity to innovate across industries: The case of an emerging economy. Industrial Marketing Management, 61, 5566. doi:10.1016/j.indmarman.2016.10.010

10. Ghobakhloo, M. (2020). Industry 4.0, digitization, and opportunities for sustainability. Journal of Cleaner Production, 252, 119869. doi:10.1016/j.jclepro.2019.119869

11. Gubová, K. (2020a). Utilisation of Technologies and Innovations in Logistics of Automotive Enterprises. AD ALTA: Journal of Interdisciplinary Research, 10(2), 91-95. doi:10.33543/1002

12. Gubová, K. (2020b). Changes in Corporate Logistics in the Slovak Wood Processing Industry. Sustainability of ForestBased Industries in the Global Economy: Proceedings of Scientific Papers, 239-243. 
13. Huggins, R., Izushi, H., Prokop, D., Thompson, P. (2015). Network evolution and the spatiotemporal dynamics of knowledge sourcing. Entrepreneurship \& Regional Development, 27(7-8), 474-499. doi:10.1080/08985626.2015.1 070538

14. Chen, K.-H., Wang, C.-H., Huang, S.-Z., Shen, G. C. (2016). Service innovation and new product performance: The influence of market-linking capabilities and market turbulence. International Journal of Production Economics, 172, 54-64. doi:10.1016/j.ijpe.2015.11.004

15. Jansen, J. J. P., Van Den Bosch, F. A. J., Volberda, H. W. (2006). Exploratory Innovation, Exploitative Innovation, and Performance: Effects of Organizational Antecedents and Environmental Moderators. Management Science, 52(11), 16611674. doi:10.1287/mnsc.1060.0576

16. Kaulartz, S., von Hippel, E. (2018). Lead User Innovation Identification: Rapid Semantic Analyses of Digital Conversations. SSRN Electronic Journal. doi:10.2139/ssrn.3249 162

17. Khan, M. K. (2019). Technological advancements and 2020. Telecommunication Systems, 73(1), 1-2. doi:10.1007/s11235019-00647-8

18. King, S., Grobbelaar, S. S. (2020). Industry 4.0 and Business Model Innovation: A Scoping Review. 2020 IEEE International Conference on Engineering, Technology and Innovation (ICE/ITMC). doi:10.1109/ice/itmc49519.2020.9198424

19. Kogabayev, T., Maziliauskas, A. (2017). The definition and classification of innovation. HOLISTICA - Journal of Business and Public Administration, 8(1), 59-72. doi:10.1515/hjbpa2017-0005

20. Martín-de Castro, G. (2015). Knowledge management and innovation in knowledge-based and high-tech industrial markets: The role of openness and absorptive capacity. Industrial Marketing Management, 47, 143-146. doi:10.1016/j.indmarm an.2015.02.032

21. OECD/Eurostat (2018). Methods for collecting, analysing and reporting statistics on business innovation. The Measurement of Scientific, Technological and Innovation Activities. doi:10.1787/g280bac11e-en

22. Piao, M., Zajac, E. J. (2015). How exploitation impedes and impels exploration: Theory and evidence. Strategic Management Journal, 37(7), 1431-1447. doi:10.1002/smj.2402

23. Prange, C., Schlegelmilch, B. B. (2016). Towards a balanced view of innovations. Management Decision, 54(2), 441-454. doi:10.1108/md-05-2015-0198

24. Rayna, T., Striukova, L., Darlington, J. (2015). Co-creation and user innovation: The role of online 3D printing platforms. Journal of Engineering and Technology Management, 37, 90102. doi:10.1016/j.jengtecman.2015.07.002

25. Scuotto, V., Shukla, S. (2015). Being Innovator or "Imovator": Current Dilemma? Journal of the Knowledge Economy, 9(1), 212-227. doi:10.1007/s13132-015-0336-6 26. Silva, F. M. da, Oliveira, E. A. de A. Q., Moraes, M. B. de. (2016). Innovation development process in small and medium technology-based companies. RAI Revista de Administração e Inovação, 13(3), 176-189. doi:10.1016/j.rai.2016.04.005

27. Smith, W. K., Tushman, M. L. (2005). Managing Strategic Contradictions: A Top Management Model for Managing Innovation Streams. Organization Science, 16(5), 522-536. doi:10.1287/orsc.1050.0134

28. Szopik-Depczyńska, K. (2015). Effects of innovation activity in industrial enterprises in Eastern Poland. Oeconomia Copernicana, 6(2), 53. doi:10.12775/oec.2015.012

29. Thiel, P., Masters, B. (2015). Zero to One : Notes on Startups, or How to Build the Future. London, Virgin Books, Cop, 2015.

30. Varsha Shree, M., Dhinakaran, V., Rajkumar, V., Bupathi Ram, P. M., Vijayakumar, M. D., Sathish, T. (2020). Effect of 3D printing on supply chain management. Materials Today: Proceedings, 21, 958-963. doi:10.1016/j.matpr.2019.09.060 31. Vial, G. (2019). Understanding digital transformation: A review and a research agenda. The Journal of Strategic Information Systems, 28(2), 118-144. doi:10.1016/j.jsis. 2019.01.003
Primary Paper Section: A

Secondary Paper Section: AE 